\title{
Serum endocan levels in women with restless legs syndrome
}

\author{
This article was published in the following Dove Press journal: \\ Neuropsychiatric Disease and Treatment \\ 19 November 2015 \\ Number of times this article has been viewed
}

Background: Endocan is a recently introduced marker of endothelial dysfunction. The objective of this study was to compare serum endocan levels in patients with restless legs syndrome (RLS) and control subjects in order to elucidate whether RLS is associated with endothelial dysfunction.

Methods: A total of 31 drug naïve female patients with RLS and 31 age- and BMI-matched women were included in the study. Patients with pathological or physiological conditions or with a history of medication use that could potentially influence endothelial functions were excluded, as well as those with alcohol or drug abuse history. The two groups were compared with routine blood tests and serum endocan levels.

Results: Patients with RLS had lower serum endocan levels than the controls $(P=0.037)$. There was a negative bivariate correlation between RLS severity score and serum endocan levels ( $r=-0.406, P=0.023$ ). While white blood cell count was significantly higher in RLS group, 25-hydroxy vitamin D3, vitamin B12, transferrin saturation rate, and HDL-cholesterol were significantly lower. Creatininemia and diastolic blood pressure were also marginally insignificantly lower in RLS group. Due to the presence of differences between two groups in these variables, a linear regression analysis was performed that showed a positive association between endocan and creatininemia $(\beta=0.310, P=0.022)$, and a negative association between endocan and RLS $(\beta=-0.502, P<0.001)$.

Conclusion: The results of this study seem to suggest that patients with RLS may have better endothelial functions when compared with the general population and that these patients may be better protected against atherosclerosis.

Keywords: endocan, restless legs syndrome, RLS, atherosclerosis, endothelial

\section{Introduction}

Restless leg syndrome (RLS) is a sensory-motor disorder characterized by intense, unpleasant, disagreeable sensations (paresthesia and dysesthesia) in the extremities (mostly in legs), which begin or worsen in the evening or at night during the periods of rest and which are relieved by movement. ${ }^{1}$ It affects approximately $5 \%-15 \%$ of the general population, ${ }^{1}$ and the diagnosis is based on clinical features. ${ }^{1}$ Proposed pathogenetic mechanisms for RLS symptoms include the dopaminergic dysfunction, occurring either primarily or triggered by iron deficiency on the background of genetic predisposition. . $^{2,3}$ Also, RLS has been reported to be associated with a number of conditions, including diabetes mellitus, obesity, hypertension, and hyperlipidemia. ${ }^{45} \mathrm{With}$ regard to the cardiovascular risk, while some authors have reported an increased cardiovascular risk in RLS patients, ${ }^{5-10}$ others have found no such association. ${ }^{11-14}$ Furthermore, RLS has even been proposed to confer protective effects against atherosclerosis. ${ }^{15,16}$ Recent studies have shown that vascular endothelium plays a fundamental role in processes such as inflammation, coagulation, angiogenesis, and tumor invasion, through the
Correspondence: Mehmet A Cikrikcioglu Department of Internal Medicine, Medical Faculty, Bezmialem Vakif University, 34093 Fatih, Istanbul, Turkey

Tel +90212453 I700

Fax +90 2I2 62I 7580

Email malicikrikcioglu@yahoo.com
Neuropsychiatric Disease and Treatment 2015:II 2919-2925 
release of a variety of mediators and through receptor/ligand interactions. ${ }^{17}$ One such molecule released by the endothelial cells is endocan, ${ }^{17}$ the increased tissue expression or serum levels of which may be an indicator of endothelial activation (inflammation) and neovascularization (tumor progression). ${ }^{18}$ The close association between endothelial dysfunction and atherosclerosis is well established, ${ }^{17}$ and elevated serum endocan levels may be a sign of increased disposition to the development of atherosclerosis. ${ }^{17}$ Patients with diabetes mellitus, acute coronary syndrome, or hypertension have been shown to have elevated serum endocan levels. ${ }^{19-21}$ In addition, a reduction in endocan levels has been observed when hypertension or diabetes is well controlled. ${ }^{19-21}$ In this study, our objective was to compare serum endocan levels in women with or without RLS, to elucidate whether RLS is associated with endothelial dysfunction in female patients. To the best of our knowledge, endocan levels have not been previously reported in patients with RLS.

\section{Methods}

\section{Study design}

This was a prospective cross-sectional case-control study.

\section{Study population}

Successive drug-naive patients attending to the neurology outpatient unit of Bezmialem Vakif University between January 2015 and May 2015 were included in this study if they met the inclusion and exclusion criteria and provided written informed consent. Similarly, successive age- and BMI-matched women attending the internal medicine outpatient department during the same time interval served as control subjects if they met the inclusion and exclusion criteria in addition to providing written informed consent.

\section{Inclusion criteria}

The patient group consisted of women with or without iron deficiency anemia between 18 and 80 years of age who fulfilled the four main criteria proposed by the International Restless Legs Syndrome Study Group (IRLSSG) for establishing a diagnosis of RLS and who had never received previous treatment for RLS (eg, iron, dopamine agonists, opioids, antiepileptics). ${ }^{22}$ These four criteria include 1) an urge to move the limbs with or without sensations; 2) worsening at rest; 3) improvement with activity; and 4) worsening in the evening or night. ${ }^{22}$ Age- and BMI-matched women without RLS served as controls, regardless of their iron level status.

\section{Exclusion criteria}

Patients with the following conditions were excluded from the study: pregnancy, lactation, chronic kidney disease (stage $\geq 3$ ), diabetes mellitus, hypertension, mood disorders, and/or psychosis, using antidepressants and/or antipsychotics and/or lithium, using antiepileptics and/or opioids and/or dopaminergic drugs, alcohol addiction, drug addiction, pituitary dysfunction, thyroid dysfunction, primary parathyroid dysfunction, adrenal dysfunction, using oral contraceptives, using postmenopausal hormone replacement therapy, being bed-ridden, history of major surgery, chronic or acute infections, cerebrovascular accident, ischemic heart disease, peripheral arterial disease, venous thrombosis, chronic venous insufficiency, heart failure, COPD, asthma, obstructive sleep apnea syndrome, dementia syndromes, Parkinson's disease, multiple sclerosis, inflammatory bowel disease, collagen tissue disorders, Sarcoidosis, chronic hepatitis, portal hypertension, hemolytic anemia, hematological malignancy, solid tumors, using antihyperlipidemic drugs, using corticosteroids or immunosuppressive drugs.

\section{Blood sampling}

Venous blood sampling carried out in the early morning after overnight fasting, complete blood cell (CBC), routine biochemistry, 25-hydroxy vitamin D3, parathormone, ferritine, and thyroid hormone measurements as well as hormone analyses were performed on the same day of sample collection. Sera were stored at $-80^{\circ} \mathrm{C}$ for endocan assay, which was carried out in the whole group of samples at a later date.

\section{Blood analysis}

A CBC analysis was performed using a Sysmex XT 1800i device (Roche-2011, Kobe, Japan). Biochemical analyses were carried out with a COBAS 8000 device (Roche-2007, Tokyo, Japan) and COBAS-C system kits. 25-Hydroxy vitamin D3 levels were determined using commercial kits (Roche-2014, Mannheim, Germany) with a COBAS E 601 hormone analyzer (Roche-2010, Tokyo, Japan). Thyroid hormone levels were determined using Advia Centaur (Advia2013, Tarrytown, NY, USA) kits, whereas parathyroid was assayed using intact parathormon kits (Abbott Company, 2014-Bayswater, VIC, Australia). Ferritin determination was done using ferritin kits (2014-Bayswater, VIC, Australia) with an Advia Centaur (2006, Dublin, Ireland) device.

\section{ELISA assay}

Following overnight fasting, venous blood samples were collected into gel tubes. A 20-minute time interval was allowed 
for coagulation, which was followed by centrifugation at $1,500 \times g$ for 15 minutes. Sera stored at $-80^{\circ} \mathrm{C}$ and on the day of the assay, concentrations of endocan in serum were measured with enzyme linked immunosorbent assay (ELISA) kit, according to protocols provided by manufacturers (Human Endocan Elisa Kit, Sunred Biological Technology, lot no: 201506, Shanghai, People's Republic of China). Multiskan FC $^{\circledR}$ Microplate Photometer (Thermo Fisher Scientific, Waltham, MA, USA) was used for reading at $450 \mathrm{~nm}$. The results were expressed in $\mathrm{ng} / \mathrm{mL}$.

\section{Patient assessments}

From each patient, past medical history and family history were obtained. The period before the diagnosis of RLS was established was recorded in months. The severity of RLS symptoms was assessed using the RLS severity scale developed by the IRLSSG, and John Hopkins RLS severity scale. ${ }^{23,24}$ Smoking status, age at menarche, menopausal status (spontaneous or surgical menopause, age at menopause), number of abortions and/or stillbirths, duration of breast feeding, number of births, average monthly income, educational status, and employment status (eg, housewife, retired, etc). A systemic physical examination was performed. Current medical treatments and comorbid conditions were determined. Blood pressure measurements were performed on the right arm in the early morning hours before blood sampling with the use a mechanic sphygmomanometer after 15 minutes of rest. BMI was calculated using the following formula:

$$
\text { BMI = body weight }(\mathrm{kg}) / \text { height } \times \text { height (meters). }
$$

\section{Statistical analyses}

Numerical variables are presented as means with standard deviation, and nominal variables in ratios. Subjects recruited to the study were divided into two groups: RLS and control groups. Nominal independent variables were compared between the groups using the chi-square test. One sample Kolmogorov-Smirnov test was performed to determine whether the continuous (numerical) independent variables were normally distributed. Normally distributed independent continuous variables were compared with Student's $t$-test, whereas non-normally distributed independent continuous variables were compared with Mann-Whitney $U$-test between the groups. Bivariate correlations were sought, and linear regression analysis was also performed. A twotailed $P$-value of $<0.05$ was considered to be statistically significant.

\section{Ethical considerations}

The study was approved by Bezmialem Vakif University Medical Faculty Ethics Committee, and all subjects recruited to the study provided informed consent. The study procedures were performed in accordance with Declaration of Helsinki 2009.

\section{Results}

The study population comprised 31 women with RLS and 31 female subjects, who served as controls. The mean age was $45.46 \pm 12.6$ years (range: $25-73$ years), and the mean BMI was $27.90 \pm 3.82 \mathrm{~kg} / \mathrm{m}^{2}$ (BMI range: $20.6-35.8 \mathrm{~kg} / \mathrm{m}^{2}$ ). The two groups were comparable in terms of age and BMI (Table 1).

In addition, there were no significant between-group differences in age at menarche, number of subjects in menopause, age at menopause, number of surgical menopause, number of births, number of abortions and/or curettage, and total duration of breastfeeding (Table 1).

Again, the two groups were comparable in terms of average monthly income level, education status, employment status (employed, housewife, retired, etc) (Tables 1 and 2),

Table I Some features of subject included in the study

\begin{tabular}{|c|c|c|c|c|}
\hline Variables & RLS: 3 I subjects & Controls: 3 I subjects & $P$-value & Type of distribution \\
\hline Age, years & $43.6 I \pm 10.51$ & $45.64 \pm 14.43$ & 0.529 & ND \\
\hline $\mathrm{BMI}$ & $28.02 \pm 3.65$ & $27.77 \pm 4.04$ & 0.800 & ND \\
\hline Blood pressure, systolic, $\mathrm{mmHg}$ & $|23.44 \pm| 3.3 \mid$ & $124.38 \pm 13.46$ & 0.805 & ND \\
\hline Blood pressure, diastolic, $\mathrm{mmHg}$ & $68.89 \pm 8.46$ & $73.54 \pm 10.16$ & 0.081 & ND \\
\hline No of births & $2.32 \pm 1.17$ & $2.81 \pm 1.80$ & 0.213 & ND \\
\hline No of abortion or curettage & $0.99 \pm 1.43$ & $0.94 \pm 1.37$ & 0.871 & NND \\
\hline Age at menarche, years & $13.97 \pm 1.43$ & $13.45 \pm 1.00$ & 0.104 & ND \\
\hline Age at menopause, years & $45.83 \pm 6.85$ & $49.60 \pm 4.14$ & 0.261 & ND \\
\hline Duration of breastfeeding & $29.36 \pm 25.70$ & $37 \pm 31.00$ & 0.295 & ND \\
\hline Monthly income, TL & $2,235.48 \pm I, \mid 47.33$ & $2,282.26 \pm 1,084.63$ & 0.870 & ND \\
\hline
\end{tabular}

Abbreviations: BMI, body mass index; ND, normal distribution; NND, non-normal distribution; RLS, restless leg syndrome; TL, Turkish lira. 
Table 2 Menopause, comorbidities, smoking, and working status of subjects included in the study

\begin{tabular}{llll}
\hline Variable number & $\begin{array}{l}\text { RLS: 3 I } \\
\text { subjects }\end{array}$ & $\begin{array}{l}\text { Controls: 3 I } \\
\text { subjects }\end{array}$ & P-value \\
\hline $\begin{array}{l}\text { Number of subjects } \\
\text { in menopause }\end{array}$ & 6 & 8 & 0.544 \\
$\begin{array}{l}\text { Number of surgical } \\
\text { menopause }\end{array}$ & 0 & I & I \\
Smokers, $\mathrm{n}$ & 12 & 9 & 0.373 \\
$\begin{array}{l}\text { Ex-smokers, } \mathrm{n} \\
\text { Housewives, } \mathrm{n}\end{array}$ & $\mathrm{I}$ & 2 & $\mathrm{I}$ \\
Workers, $\mathrm{n}$ & 23 & 24 & 0.767 \\
Pensioners, $\mathrm{n}$ & 7 & 5 & 0.520 \\
\hline
\end{tabular}

Abbreviation: RLS, restless leg syndrome. as well as in terms of the proportion women who are current or ex-smokers (Table 2).

Laboratory parameters, including total protein, albumin, ALT, AST, LDL-cholesterol, triglycerides, alkaline phosphatase, gamma-glutamyl transpeptidase, PTH, thyroid hormones, ferritin, folic acid, hemoglobin, platelet, CRP, and erythrocyte sedimentation rate did not differ significantly between the two groups (Table 3).

However, a significantly lower serum endocan level was found in RLS patients (Table 3), and there was a negative bivariate correlation between IRLSSG severity score and endocan levels $(r=-0.406, P=0.023)$.

Table 3 Blood analysis in both groups

\begin{tabular}{|c|c|c|c|c|c|}
\hline Variables & $\begin{array}{l}\text { RLS: } 3 \text { I subjects, } \\
\text { mean } \pm \text { SD }\end{array}$ & $\begin{array}{l}\text { Controls: } 3 \text { I subjects, } \\
\text { mean } \pm \text { SD }\end{array}$ & $\begin{array}{l}\text { Reference } \\
\text { value }\end{array}$ & $P$-value & $\begin{array}{l}\text { Type of } \\
\text { distribution }\end{array}$ \\
\hline $\mathrm{RBC} \times 10^{12} / \mathrm{L}$ & $4.66 \pm 0.47$ & $4.58 \pm 0.33$ & $4.0-6.2$ & 0.446 & ND \\
\hline $\mathrm{Hb}, \mathrm{g} / \mathrm{L}$ & $12.24 \pm 1.75$ & $12.67 \pm 1.23$ & $130-175$ & 0.271 & ND \\
\hline Htc, \% & $38.04 \pm 4.17$ & $38.78 \pm 3.23$ & $40-52$ & 0.444 & ND \\
\hline $\mathrm{MCV}, \mathrm{fL}$ & $81.94 \pm 8.65$ & $84.57 \pm 39.4$ & $80-100$ & 0.131 & ND \\
\hline $\mathrm{MCH}, \mathrm{pg}$ & $26.38 \pm 3.85$ & $27.62 \pm 1.70$ & $27-34$ & 0.111 & ND \\
\hline WBC, $\times 10^{9} / \mathrm{L}$ & $8.04 \pm 2.47$ & $6.82 \pm 1.75$ & $3.8-10.0$ & 0.031 & ND \\
\hline Platelets, $\times 10^{9} / \mathrm{L}$ & $280.68 \pm 65.98$ & $257.83 \pm 57.31$ & $150-400$ & 0.155 & ND \\
\hline $\mathrm{MPV}, \mathrm{fL}$ & $10.44 \pm 0.72$ & $10.27 \pm 1.32$ & $9-17$ & 0.536 & ND \\
\hline Albumin, g/L & $44.00 \pm 2.63$ & $43.30 \pm 2.30$ & $35-50$ & 0.293 & ND \\
\hline Total protein, $g / L$ & $72.80 \pm 3.60$ & $73.60 \pm 4.60$ & $60-80$ & 0.463 & ND \\
\hline Calcium, mmol/L & $2.37 \pm 0.10$ & $2.39 \pm 0.09$ & $2.05-2.55$ & 0.560 & ND \\
\hline Phosphorus, mmol/L & $1.12 \pm 0.16$ & $1.17 \pm 0.14$ & $0.74-1.52$ & 0.235 & ND \\
\hline Parathormone, ng/L & $55.32 \pm 21.99$ & $63.60 \pm 32.10$ & $10-65$ & 0.241 & ND \\
\hline 25-hydroxy vitamin D3, nmol/L & $37.74 \pm 35.42$ & $60.20 \pm 56.18$ & $35-150$ & 0.017 & NND \\
\hline Alkaline phosphatase, U/L & $65.23 \pm 17.08$ & $70.29 \pm 22.85$ & $30-120$ & 0.333 & ND \\
\hline$\gamma$-glutamyl transpeptidase, $\mathrm{U} / \mathrm{L}$ & $21.81 \pm 15.36$ & $18.42 \pm 10.63$ & $0-45$ & 0.317 & ND \\
\hline $\mathrm{ESR}, \mathrm{mm} / \mathrm{h}$ & $24.26 \pm 16.12$ & $22.29 \pm 15.26$ & $<20$ & 0.623 & ND \\
\hline CRP, nmol/L & $5.62 \pm 11.14$ & $2.38 \pm 2.57$ & $0.76-28.5$ & 0.848 & NND \\
\hline Creatinine, micromoles/L & $51.27 \pm 13.26$ & $58.34 \pm 16.80$ & $53-106$ & 0.076 & NND \\
\hline Glucose, $\mathrm{mmol} / \mathrm{L}$ & $5.31 \pm 0.86$ & $5.59 \pm 1.94$ & $3.9-6.1$ & 0.647 & NND \\
\hline $\mathrm{HbA}_{\mathrm{IC}}, \%$ & $5.69 \pm 0.64$ & $5.63 \pm 0.67$ & $4.5-5.7$ & 0.360 & NND \\
\hline LDL-cholesterol, mmol/L & $3.4 I \pm 0.82$ & $3.51 \pm 1.27$ & 4.144 & 0.724 & ND \\
\hline HDL-cholesterol, $\mathrm{mmol} / \mathrm{L}$ & $1.32 \pm 0.31$ & $1.50 \pm 0.37$ & $<1.03$ & 0.041 & ND \\
\hline Triglyceride, $\mathrm{mmol} / \mathrm{L}$ & $1.8 \mathrm{I} \pm \mathrm{I} .15$ & $\mathrm{I} .44 \pm 0.90$ & 1.8 & 0.167 & ND \\
\hline AST, IU/L & $21.97 \pm 10.32$ & $20.87 \pm 10.77$ & $10-30$ & 0.684 & NND \\
\hline ALT, IU/L & $22.29 \pm 14.90$ & $24.94 \pm 26.94$ & $10-40$ & 0.634 & NND \\
\hline Transferrin saturation rate, $\%$ & $17.13 \pm 14.40$ & $23.80 \pm 11.11$ & $20-40$ & 0.046 & ND \\
\hline Ferritin, ng/mL & $92.76 \pm 204.14$ & $84.26 \pm 72.04$ & $33-450$ & 0.094 & NND \\
\hline Vitamin BI2, pmol/L & $231.88 \pm 73.54$ & $277.43 \pm 91.16$ & || $8-70 \mid$ & 0.034 & ND \\
\hline Folic acid, nmol/L & $19.28 \pm 7.30$ & $17.88 \pm 8.72$ & $7-36$ & 0.494 & ND \\
\hline $\mathrm{TSH}, \mathrm{mIU} / \mathrm{L}$ & $2.38 \pm 1.59$ & $2.21 \pm 1.25$ & $0.63-4.82$ & 0.634 & ND \\
\hline $\mathrm{FT} 3, \mathrm{pmol} / \mathrm{L}$ & $4.32 \pm 0.60$ & $4.62 \pm 0.67$ & $3.5-6.5$ & 0.067 & ND \\
\hline $\mathrm{FT} 4, \mathrm{pmol} / \mathrm{L}$ & $13.19 \pm 2.62$ & $13.99 \pm 1.95$ & $10-18.7$ & 0.176 & ND \\
\hline Endocan, $\mathrm{ng} / \mathrm{mL}$ & $212.18 \pm 43.59$ & $387.91 \pm 340.58$ & Unknown & 0.037 & NND \\
\hline
\end{tabular}

Abbreviations: ALT, alanin transaminase; AST, aspartat transaminase; CRP, c reactive protein; ESR, erythrocyte sedimentation rate; FT3, free three iodothyronin; FT4, free thyroxine; Hb, hemoglobin; $\mathrm{HbA}_{I C}$, hemoglobin AIC; HDL, high-density lipoprotein; Htc, hematocrit; LDL, low-density lipoprotein; MCH, mean corpuscular hemoglobin; MCV, mean corpuscular volume; MPV, mean platelet volume; ND, normal distribution; NND, non-normal distribution; RBC, red blood cell; RLS, restless leg syndrome; WBC, white blood cell; TSH, thyroid stimulating hormone. 
Table 4 Linear regression analysis

\begin{tabular}{|c|c|c|c|c|c|}
\hline \multirow{2}{*}{$\begin{array}{l}\text { Independent } \\
\text { variables }\end{array}$} & \multicolumn{2}{|c|}{ Unstandardized coefficients } & \multirow{2}{*}{$\begin{array}{l}\text { Standardized coefficients } \\
\text { Beta }\end{array}$} & \multirow[t]{2}{*}{$\boldsymbol{t}$} & \multirow[t]{2}{*}{ Significance } \\
\hline & B & SE & & & \\
\hline Constant & 220.057 & 150.063 & - & 1.466 & 0.149 \\
\hline Presence of RLS & -281.896 & 73.732 & -0.502 & -3.823 & $<0.001$ \\
\hline Creatininemia & 495.656 & 209.826 & 0.310 & 2.362 & 0.022 \\
\hline
\end{tabular}

Notes: Dependent variable was endocan. $R^{2}: 0.264$; adjusted $R^{2}: 0.233$. F: 8.27I.

Abbreviation: RLS, restless leg syndrome.

Systolic blood pressure was similar in the two groups, and the diastolic blood pressure was lower in RLS subjects, but the difference was marginally insignificant (Table 1). White blood cell (WBC) count was significantly higher; HDL-cholesterol, 25-hydroxy vitamin D3, transferrin saturation rate, and vitamin B12 were significantly lower among RLS subjects; creatinine level was also lower in RLS patients with the difference being marginally insignificant (Table 3). Due to these findings, a linear regression analysis was performed, which did not show any correlation between the dependent variable of endocan and diastolic blood pressure $(P=0.131)$, HDL-cholesterol $(P=0.358), 25$-hydroxy vitamin $\mathrm{D} 3(P=0.385)$, transferrin saturation rate $(P=0.705)$, WBC count $(P=0.534)$, and vitamin B12 $(P=0.417)$, while it was significantly associated with the independent variable of RLS and creatinine levels (Table 4).

The average disease severity score according to IRLSSG criteria was $28.87 \pm 5.51$ (range: $17-39$ ), corresponding to moderate RLS. Among patients who could be assessed according to John Hopkins disease severity criteria, 38.7\%, $48.4 \%$, and $12.9 \%$ of the patients had mild, moderate, or severe RLS, respectively. The average duration of RLS was $44.43 \pm 30.60$ months (range: $12-120$ months).

\section{Discussion}

Patients with RLS may experience complete or partial symptomatic improvement during day hours due to factors such as movement, mental work, excitement, ${ }^{25}$ which increase the sympathetic activity ${ }^{26,27}$ leading to increased cortisol release. In turn, cortisol may enhance the sympathetic nervous system activity through positive feedback mechanisms. ${ }^{25}$ Increased sympathetic activity and cortisol release may exert some positive effects on the dopaminergic activity in the brain, ${ }^{25}$ resulting in a temporary alleviation of RLS symptoms and dopaminergic dysfunction. ${ }^{25}$ Therefore, patients with RLS tend to increase their physical or mental activities intentionally or unintentionally. ${ }^{25}$ Accordingly, an increase in sympathetic nervous system activity was shown in RLS patients using of heart rate variability analysis. ${ }^{25}$ The exact mechanisms of nocturnal worsening in RLS symptoms are unknown, and were thought to be associated with melatoninrelated mechanisms. ${ }^{25}$ Cortisol and dopamine release in humans follow a parallel circadian pattern, ${ }^{25}$ which is opposite to the circadian pattern of RLS symptoms..$^{25}$ One of the reasons for the physiological decline in dopamine release is the reduction in cortisol secretion during night hours and increased parasympathetic nervous system activity. ${ }^{25}$ This mechanism may be responsible for the increase in the severity of RLS symptoms in the night hours. ${ }^{25}$ Patients with RLS tend to maintain a continuous level of activity and move their legs in the bed until the time of daybreak (where the cortisol levels reach a peak) in an effort to alleviate RLS symptoms. ${ }^{25}$ In turn, this may reduce the parasympathetic nervous system activity, and increase the sympathetic nervous system activity and cortisol release, influencing the circadian rhythm of cortisol and autonomous nervous system. Low dose corticosteroid infusion administered at night hours has been shown to reduce RLS symptoms. ${ }^{28}$ In a recent study, RLS patients have been shown to have higher overnight urinary cortisol excretion when compared with control subjects. ${ }^{29}$

Increased sympathetic activity and corticosteroid release are known to exert adverse effects on endothelial functions, ${ }^{30-32}$ whereas exercise has positive effects on endothelial functions with atheroprotective properties. ${ }^{33,34}$ Although increased physical activity may be associated with increased sympatho-adrenal activity, it may also have a positive effect on endothelial functions. We think that this may, at least partially, explain the lower serum endocan levels in RLS patients.

Wahlin-Larsson et $\mathrm{al}^{35}$ in a study, examining the skeletal muscle morphology in RLS patients, found an increased microvessel tortuosity. The authors pointed out the possible occurrence of symptoms due to disturbed balance of vasoconstriction/vasodilation and mentioned that regulation of this balance through the movements of extremity may be responsible for the relief experienced by the patients. Flow-induced laminar shear stress at the vessel wall induced by exercise is a potent physiological stimulant for the exercise-related atheroprotective effects. This mechanism may also reduce the endocan levels in RLS patients. 
Recently, in a study, Park et al ${ }^{36}$ detected significantly lower carotid intima-media thickness, a marker of atherosclerosis, among patients with RLS when compared with controls and stated that this may reflect a low risk of atherosclerotic progression in this group of patients. Although the risk of atherosclerosis and related cerebrovascular disease risk are lower in Parkinson's disease, which shares certain common pathophysiological features with RLS, Parkinson's patients receiving L-DOPA are known to develop atherosclerosis due to the secondary hyperhomocysteinemia induced by L-DOPA. ${ }^{3}$ In a similar study, increase in intima-media thickness was found among PD patients on L-DOPA. ${ }^{37}$ Probably, absolute and functional dopamine deficiency in the central nervous system may be associated with a lower risk of atherosclerosis in RLS and Parkinson's disease; however, this theory requires further clarification. However, the results of the above-mentioned studies are supportive of our observations.

The two study groups had certain differences that could affect endothelial functions. These included lower 25-hydroxy vitamin D3, diastolic blood pressure, HDL cholesterol, transferrin saturation rate, vitamin B12, and creatinine, and higher WBC count among RLS patients. The linear regression analysis was performed to account for these factors. Endocan was not associated with diastolic blood pressure, vitamin B12, 25-hydroxy vitamin D3, HDLcholesterol, transferrin saturation rate, and WBC. Endocan correlated positively with serum creatinine and negatively with the presence of RLS.

Consistent with our observations, an increase in serum endocan levels paralleling the increase in serum creatinine levels has been demonstrated previously. ${ }^{38}$ The highest level of endocan expression has occurred in the peritubular cells of the cortex and renal medulla. ${ }^{38}$ Reduced clearance or increased secretion may be responsible for the elevation in endocan levels in patients with renal failure. ${ }^{38}$ It has also been proposed that serum endocan levels may in the future be utilized as a marker for renal functions, such the estimated glomerular filtration rate or proteinuria. ${ }^{38}$ In all stages of chronic renal failure, the presence of a positive correlation between serum endocan levels and inflammation, carotid intima-media thickness (a surrogate marker for atherosclerosis), incidence of cardiovascular events, and mortality rate has been shown. ${ }^{38}$

Lower levels of creatininemia among RLS patients than among controls does not represent a potential explanation for the lower endocan levels in our RLS patients when compared with controls, since, according to the linear regression analysis, the two independent variables, ie, creatininemia (positively correlated with the endocan-dependent variable) and being an RLS patient (negatively correlated with the endocan-dependent variable), were independently associated with serum endocan. Even in the presence of an association between the independent variables of creatininemia and being an RLS patient, there can be no cause and effect relationship between the two. In other words, if endocan levels were lower in RLS patients due to low creatinine levels, then according to a regression analysis the only independent variable correlated with endocan would be creatininemia and the variable of "being a RLS patient" would have been eliminated.

A major limitation of our study is its small sample size.

\section{Conclusion}

Female RLS patients seem to have lower degrees of endothelial dysfunction when compared with women without RLS. Increased physical activity and functional dopamine deficiency may play a role in this observation. Our results suggest a lower degree of predisposition to atherosclerosis in RLS patients than in non-RLS individuals. Cross-sectional studies involving larger patient populations and studies looking at the changes in endocan levels after treatment in RLS patients are warranted.

\section{Disclosure}

The authors report no conflicts of interest in this work.

\section{References}

1. Cikrikcioglu MA, Halac G, Hursitoglu M, et al. Prevalence of gluten sensitive enteropathy antibodies in restless legs syndrome. Acta Neurol Belg. 2011;111(4):282-286.

2. Hogl B, Kiechl S, Willeit J, et al. Restless legs syndrome: a communitybased study of prevalence, severity, and risk factors. Neurology. 2005; 64:1920-1924.

3. Allen R. Dopamine and iron in the pathophysiology of restless legs syndrome. Sleep Med. 2004;5(4):385-391.

4. Baskol G, Korkmaz S, Erdem F, et al. Assessment of nitricoxide, advanced oxidation protein products, malondialdehyde, and thiol levels in patients with restless legs syndrome. Sleep Med. 2012;13:414-418.

5. Innes KE, Selfe TK, Agarwal P. Restless legs syndrome and conditions associated with metabolic dysregulation, sympathoadrenal dysfunction, and cardiovascular disease risk: a systematic review. Sleep Med Rev. 2012; 16:309-339.

6. Walters AE, Rye DB. Review of the relationship of restless legs syndrome and periodic limb movements in sleep to hypertension, heart disease, and stroke. Sleep. 2009;32(5):589-597.

7. Ulfberg J, Nystrom B, Carter N, et al. Prevalence of restless legs syndrome among men aged 18 to 64 years: an association with somatic disease and neuropsychiatric symptoms. Mov Disord. 2001;16:1159-1163.

8. Ohayon MM, Roth T. Prevalence of restless legs syndrome and periodic limb movement disorder in the general population. J Psychosom Res. 2002;53:547-554.

9. Winkelman JW, Finn L, Young T. Prevalence and correlates of restless legs syndrome symptoms in the Wisconsin sleep cohort. Sleep Med. 2006; $7: 545-552$. 
10. Li Y, Walters AS, Chiuve SE, et al. Prospective study of restless legs syndrome and coronary heart disease among women. Circulation. 2012;126: 1689-1694.

11. Elwood P, Hack M, Pickering J, Hughes J, Gallacher J. Sleep disturbance, stroke, and heart disease events: evidence from the Caerphilly cohort. J Epidemiol Community Health. 2006;6069-6073.

12. Winter AC, Schürks M, Glynn RJ, et al. Restless legs syndrome and risk of incident cardiovascular disease in woman and men; prospective cohort study. BMJ Open. 2012;2:e000866.

13. Winter AC, Schürks M, Glynn RJ, et al. Vascular risk factors, cardiovascular disease and restless legs syndrome in women. Am JMed. 2013;126(3): 220-2276.

14. Benediktsdottir B, Janson C, Lindberg E, et al. Prevalence of restless legs syndrome among adults in Iceland and Sweden: lung function, comorbidity, ferritin, biomarkers and quality of life. Sleep Med. 2010;11: 1043-1048.

15. Park JH, Han SW, Baik JS. Carotid intima-media thickness in patients with idiopathic restless legs syndrome. Eur Neurol. 2012;67(6) 321-325.

16. Q-Jacobo K, Monge A, Ortiz-Panozo E, et al. Abstract P074: restless legs syndrome and carotid intima-media thickness in women circulation. Sleep. 2015;131.

17. Afsar B, Takir M, Kostek O, Covic A, Kanbay M. Endocan: a new molecule playing a role in the development of hypertension and chronic kidney disease? J Clin Hypertens (Greenwich). 2014;16(12):914-916. doi:10.1111/jch.12440.

18. Kali A, Shetty KS. Endocan: a novel circulating proteoglycan. Indian J Pharmacol. 2014;46(6):579-583. doi:10.4103/0253-7613.144891.

19. Celik T, Balta S, Karaman M, et al. Endocan, a novel marker of endothelial dysfunction in patients with essential hypertension: comparative effects of amlodipine and valsartan. Blood Press. 2015;24(1):55-60. doi:10.3109/08037051.2014.972816.

20. Wang XS, Yang W, Luo T, Wang JM, Jing YY. Serum endocan levels are correlated with the presence and severity of coronary artery disease in patients with hypertension. Genet Test Mol Biomarkers. 2015; 19(3):124-127. doi:10.1089/gtmb.2014.0274.

21. Arman Y, Akpinar TS, et al. Effect of glycemic regulation on endocan levels in patients with diabetes: a preliminary study. Angiology. 2015. pii: 0003319715585664. [Epub ahead of print]

22. Ondo WG. Restless legs syndrome. Neurol Clin. 2009;27(3):779-799, vii.

23. Walters AS, LeBrocq C, Dhar A, et al. Validation of the international restless legs syndrome study group rating scale for restless legs syndrome; International Restless Legs Syndrome Study Group. Sleep Med. 2003; 4(2):121-132.

24. Allen RP, Earley CJ. Validation of the Johns Hopkins restless legs severity scale. Sleep Med. 2001;2(3):239-242.
25. Cikrikcioglu MA, Hursitoglu M, Erkal H, et al. Oxidative stress and autonomic nervous system functions in restless legs syndrome. Eur J Clin Invest. 2011;41(7):734-742. doi:10.1111/j.1365-2362.2010.02461.x.

26. Péronnet F, Cleroux J, Perrault H, et al. Plasma norepinephrine, epinephrine, and dopamine beta-hydroxylase activity during exercise in man. Med Sci Sports Exerc. 1985;17(6):683-688.

27. Mönnikes H, Koop H, Ehlenz K, Dionysius J, Arnold R. Role of circulating catecholamines in the control of pancreatic polypeptide and gastrin release. Res Exp Med (Berl). 1989;189(3):181-187.

28. Hornyak M, Rupp A, Riemann D, Feige B, Berger M, Voderholzer U. Low-dose hydrocortisone in the evening modulates symptom severity in restless legs syndrome. Neurology. 2008;70(18):1620-1622.

29. Schilling C, Schredl M, Strobl P, Deuschle M. Restless legs syndrome: evidence for nocturnal hypothalamic-pituitary-adrenal system activation. Mov Disord. 2010;25(8):1047-1052.

30. Lambert EA, Teede H, Sari CI, et al. Sympathetic activation and endothelial dysfunction in polycystic ovary syndrome are not explained by either obesity or insulin resistance. Clin Endocrinol (Oxf). 2015. doi:10.1111/cen.12803. [Epub ahead of print]

31. Balkaya M, Prinz V, Custodis F, et al. Stress worsens endothelial function and ischemic stroke via glucocorticoids. Stroke. 2011;42(11): 3258-3264.

32. Chandran DS, Jaryal AK, Jyotsna VP, Deepak KK. Impaired endothelium mediated vascular reactivity in endogenous Cushing's syndrome. Endocrinol J. 2011;58(9):789-799.

33. Beck DT, Casey DP, Martin JS, Emerson BD, Braith RW. Exercise training improves endothelial function in young prehypertensives. Exp Biol Med (Maywood). 2013;238(4):433-441. doi:10.1177/1535370213477600.

34. Sprung VS, Cuthbertson DJ, Pugh CJ, et al. Nitric oxide-mediated cutaneous microvascular function is impaired in polycystic ovary syndrome but can be improved by exercise training. J Physiol. 2013; 591(Pt 6):1475-1487. doi:10.1113/jphysiol.2012.246918.

35. Wahlin-Larsson BW, Kadi F, Ulfberg J, Aulin KP. Skeletal muscle morphology in patients with restless legs syndrome. Eur Neurol. 2007;58: 133-137.

36. Bostantjopoulou S, Katsarou Z, Frangia T, et al. Endothelial function markers in parkinsonian patients with hyperhomocysteinemia. J Clin Neurosci. 2005;12(6):669-672.

37. Nakaso K, Yasui K, Kowa H, et al. Hypertrophy of IMC of carotid artery in Parkinson's disease is associated with L-DOPA, homocysteine, and MTHFR genotype. J Neurol Sci. 2003;207:19-23.

38. Yilmaz MI, Siriopol D, Saglam M, et al. Plasma endocan levels associate with inflammation, vascular abnormalities, cardiovascular events, and survival in chronic kidney disease. Kidney Int. 2014;86(6):1213-1220.
Neuropsychiatric Disease and Treatment

\section{Publish your work in this journal}

Neuropsychiatric Disease and Treatment is an international, peerreviewed journal of clinical therapeutics and pharmacology focusing on concise rapid reporting of clinical or pre-clinical studies on a range of neuropsychiatric and neurological disorders. This journa is indexed on PubMed Central, the 'PsycINFO' database and CAS,

\section{Dovepress}

and is the official journal of The International Neuropsychiatric Association (INA). The manuscript management system is completely online and includes a very quick and fair peer-review system, which is all easy to use. Visit http://www.dovepress.com/testimonials.php to read real quotes from published authors. 